\title{
Wax On, Wax Off! \\ Habits, Sport Skills, and Motor Intentionality
}

Massimiliano Lorenzo Cappuccio ${ }^{1,2}$, Katsunori Miyahara³ ${ }^{3}$, Jesús llundáin-Agurruza ${ }^{4}$

(1) University of New South Wales Canberra, School of Engineering and Information Technology, Canberra, Australia

(2) United Arab Emirates University, Science \& Innovation Park, Al Ain, UAE

(3) Hokkaido University, Center for Human Nature, Artificial Intelligence, and Neuroscience (CHAIN), Hokkaido, Japan

(4) Linfield University, Department of Philosophy, Oregon, USA

\section{Corresponding author}

Dr. Massimiliano Lorenzo Cappuccio

Deputy Director, Values in Defence \& Security Technology Group (VDST), UNSW Canberra @ ADFA

Address: Room 370-71, Building 21, The University of New South Wales Canberra, Campbell ACT 2612, Australia

E-mail:m.cappuccio@unsw.edu.au

Website: www.unsw.adfa.edu.au/our-people/max-cappuccio

Mobile phone: $+61(0) 433900627$

\section{Abstract}

What role does habit formation play in the development of sport skills? We argue that motor habits are both necessary for and constitutive of sensorimotor skill as they support an automatic, yet inherently intelligent and flexible, form of action control. Intellectualists about skills generally assume that what makes action intelligent and flexible is its intentionality, and that intentionality must be necessarily cognitive in nature to allow for both deliberation and explicit goal-representation. Against Intellectualism we argue that the habitual behaviours that compose skilful action are accompanied by their specific, non-cognitive form of intentionality: this is motor intentionality, which is purposive and adaptive while involving 
no explicit deliberation or goal representation. Our account of habit based on Motor Intentionality explains why the formation of motor habits can sometimes act as the sole basis of skilful acquisition: Motor Intentionality is inherently purposeful because it is an embodied source of sensorimotor anticipation, pre-reflective motivation, and pragmatic know-how. Skill development through exercise always builds on a motor intentional component even when it is guided by Deliberate Practice to the point that, pace Intellectualism, Deliberate Practice is disclosed, not constrained, by habit formation. As suggested by the fact that repetitive exercises can play a major role in the development of flexible and intelligent sport skills, automatism is not a drawback for strategic control and improvisation but rather their pragmatic foundation.

\section{Keywords:}

Habit formation; Sport skill acquisition; Motor intentionality; Intellectualism; Sensorimotor action; Goal representation; Deliberate Practice; Embodied cognition. 


\section{Wax On, Wax Off! \\ Habits, Sport Skills, and Motor Intentionality}

Massimiliano Lorenzo Cappuccio, Katsunori Miyahara, Jesús Ilundáin-Agurruza

\section{Introduction}

Most of us remember the iconic (yet fictional) depiction of martial arts training offered by the Karate Kid movie (1984). To make him automatize the blocking moves instinctively produced by karatekas for stopping punches and kicks, karate master Miyagi-sensei assigns an exercise involving an endless, apparently mindless repetition of "waxing on and off" circular movements to his trainee, Daniel-san, who is unaware of this task's real purpose. Expert martial artists debate whether Miyagi's training routine is a plausible method to learn karate's blocking moves: such an exercise seems to favour selective muscular reinforcement, but can repetitive movements also support the development of a truly skilful ability if the practitioner does not know their real goal? In order to grasp the relationship between skill, movement, and knowledge we need to investigate philosophically this issue at a deeper level. We need to ask not only whether or not Miyagi's method can plausibly scaffold skill development, but also whether such method is intended to be just a mindless repetition of automatic movements, as many believe, or rather a practice that involves conscious, deliberate determination. The four combinations that result from the binary answers that can be given to these two questions define the chart below; we will use it to tentatively explore the possible links between habit and skilful performance.

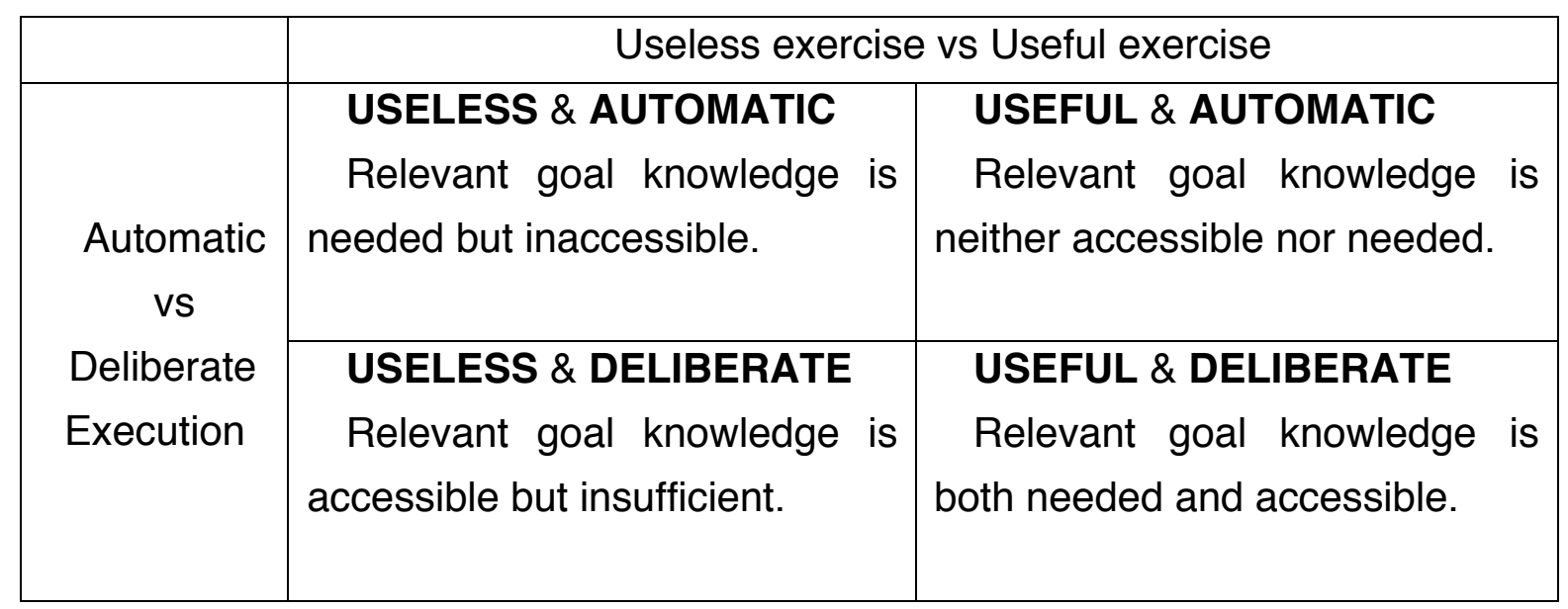

(Tab. 1) Is Miyagi-sensei's practice useful to learn a karate skill? Does it involve only automatic execution or also deliberate control? 
In section seven, below, we will use this schema to address Karate Kid's case as a thought experiment. For now we need to highlight that this case epitomizes the question asked by the sport psychologists and philosophical psychologists who investigate the impact of habit formation and Deliberate Practice on skill acquisition and, subsequently, on skilful performance (Montero 2016): what role does habit formation play in the development of sensorimotor skills, and, paradigmatically, goal-oriented skilful actions in sports? Some have answered that consolidating motor habits is necessary to acquiring sport skills and that, in some cases, building certain automated routines is sufficient to develop a new skill (Fitt \& Posner 1967). Others have pointed out that excellence in sport is neither necessarily nor primarily based on action automatization, underlining the inefficacy of the training approaches based on habit consolidation through repetitive exercise (Ericsson et al. 2006). Their prima facie disagreement essentially bears on the genesis and function of habits.

Habits are patterns of behaviour, postures, and attitudes that, having been "automatized", became spontaneous dispositions to think, act, or even experience things in specific ways in response to specific circumstances. Habitual actions can be initiated without deliberation, executed without explicitly representing their goals and effects, and controlled without analytically monitoring their execution (Robbins \& Costa 2017). Philosophical psychologists often construe automatic behaviour as a stimulus-response mechanism essentially based on invariant reflexes (Bernacer \& Murillo 2014). However, alleging that habits are inflexible, this view seems irreconcilable with the obvious fact that skilful actions are richly and intelligently adaptive.

In this paper we will argue against this view, remarking that habits can be and often are skilful, especially when they derive from the automatization of complex, intelligently adaptive actions. Sport training practices exemplify how habit formation is both necessary and constitutive for the development of sophisticated sensorimotor skills because in many cases sport skill development relies importantly, if not prevalently, on the repetition of certain motor routines without which the skill cannot be learned (Cappuccio \& Ilundáin-Agurruza 2020). Thus, if in this paper we argue that sport skills are built on habits, it is not to imply that skills are mechanical and repetitive. Rather, it is to reject the mechanistic account of habits so as to finally recognize habits as inherently intelligent and flexible - yet automatic - forms of behaviour.

Philosophers in the intellectualist tradition tend to reject this conclusion as they assume that behaviour can be intelligent and flexible only if it is informed by what they consider to be the distinctive marks of intentionality, i.e. deliberation and explicit goal-representation. Further, they argue that habitual behaviours - qua automatic - cannot be intentional because they don't carry such marks. We contest the intellectualist assumption that deliberation and explicit goal-representation are necessary to make behaviour intelligent 
and flexible, arguing that the habitual behaviours that compose skilful action are motivated by a specific form of intentionality that does not carry such marks: this is Motor Intentionality (MI), which differs from Cognitive Intentionality $(\mathrm{Cl})$ in that it is intelligent and flexible while involving no deliberate action control and no explicit representation of the action goals. An account of habit based on $\mathrm{Ml}$ explains that well-trained motor routines can scaffold skilful performance because motor intentions are legitimate sources of predictive abilities, prereflective motivation, and pragmatic know-how. This is what allows experts to act adaptively and purposively when their actions are fully automatized.

This paper is organized into eight parts. First, we revisit the philosophical debate on habit in skill to critically discuss the assumptions that motivate the customary Habitualism vs Intellectualism antagonism. Second, we situate our approach within a revised and extended cartography of intellectualist and habitualist views on sporting skill, distinguishing between traditional and reformed approaches. Third, we critically examine the Liberal Intellectualist (LIBINT) approach, which entails the mechanistic assumption that habits ere neither inherently intentional nor purposive. Fourth, we propose an embodied approach to habit, Revised Habitualism (REHAB), contrasting it with LIBINT's mechanistic view. Fifth, we delve into Maurice Merleau-Ponty's concept of MI to explain how habit holds the positive features negated by Intellectualism. Sixth, to counter LIBINT's main objection, we contend that REHAB can perfectly account for the positive role of Deliberate Practice in sport training. Seventh, we finally answer our initial question about the Karate Kid training: even without explicit goal knowledge, habitual motor routines can contribute to the development of new skillsets because they disclose a space of original opportunities for variation and creation. In the conclusion we review why some instances of habit formation through repetitive exercise are constitutive and necessary components of sport skill development.

\section{Revisiting the Intellectualism-vs-Habitualism debate}

Sport skills offer a paradigmatic example of fine-grained and well-coordinated control abilities that require focused preparation and intensive exercise to achieve the best results. Sport psychologists have long investigated the cognitive processes that underpin peak performance in sport, discussing whether optimal sensorimotor control is automatic and cognitively effortless or rather deliberate and cognitively effortful (Cappuccio et al. 2019).

This polarization transfers to the philosophical debate on the nature of skill and expertise. Papineau (2015) has characterized this debate as the antagonism between "habitualist" and "intellectualist" views on skill: for Habitualism, the distinctive mark of expertise is action automatization (Dreyfus \& Dreyfus 1967; Dreyfus 2002); for Intellectualism, self-awareness and the mastery of intelligent decision-making abilities (Montero 2010; Sutton et al. 2011). Habitualism emphasizes that sporting skill consists in a practical, bodily know-how based 
on automatic sensorimotor dispositions suitable to quickly and effortlessly respond to familiar scenarios (Kelly 2000). Intellectualism emphasizes that sporting skill ultimately requires the kind of knowledge, typically conveyed by verbal instructions or conceptual models, necessary to achieve an explicitly represented goal (McDowell 2007, Stanley \& Krakauer 2013). For the former, skilful performance relies on implicit embodied routines that tend to be damaged by over-attentive control and explicit instructions; for the latter, on strategic thinking and on-line deliberation, which are compromised when attention to ongoing action is overlooked in favour of routine behaviour. The chart below summarizes their key tenets.

\begin{tabular}{|l|l|l|}
\hline Dimension & Intellectualism & Habitualism \\
\hline Mode of execution & $\begin{array}{l}\text { Deliberate and attentively } \\
\text { controlled. }\end{array}$ & Automatic and quickly responsive. \\
\hline Phenomenology & $\begin{array}{l}\text { Self-focused attention improves } \\
\text { accuracy and efficacy. }\end{array}$ & $\begin{array}{l}\text { Self-focused attention damages } \\
\text { fluidity and rapidity. }\end{array}$ \\
\hline $\begin{array}{l}\text { Management of } \\
\text { cognitive resources }\end{array}$ & $\begin{array}{l}\text { Multi-tasking reduces } \\
\text { concentration increasing the risk } \\
\text { of distraction. }\end{array}$ & $\begin{array}{l}\text { Sensorimotor routines are not } \\
\text { disturbed by concurrent } \\
\text { Verbal/Cognitive tasks (unless such } \\
\text { tasks reflectively target the } \\
\text { sensorimotor routines themselves). }\end{array}$ \\
\hline $\begin{array}{l}\text { Performance } \\
\text { optimization/improve } \\
\text { ment }\end{array}$ & $\begin{array}{l}\text { Explicit planning/representation of } \\
\text { the action structure/goal produces } \\
\text { better performances than routine } \\
\text { behaviour. }\end{array}$ & $\begin{array}{l}\text { Execution of automatized motor skill } \\
\text { does not benefit from and often is } \\
\text { disturbed by verbal instructions or } \\
\text { self-monitoring. }\end{array}$ \\
\hline
\end{tabular}

(Tab. 2) Intellectualism vs Habitualism about skill: the standard positions.

Papineau observes that "both sides are right and wrong" (p. 297): Intellectualism is correct that "Basic Actions" (goal-oriented behaviours infused with intention and purpose) are better performed when deliberately controlled; Habitualism that the "Motor Components" of Basic Actions (the simple movements that form goal-oriented behaviours) are better performed when automatized. Sport performance typically depends on a mix of deliberate control (involving goal representation) and habitual (automatic) behaviour, the exact proportions of which vary depending on sport discipline, task at hand, and athletes' personal approaches and inclinations. We agree that each view captures some significant element of skilful performance, which is precisely why their most hard-line versions are indefensible. 
However, we think that a different way to draw the demarcation between Habitualism and Intellectualism is both possible and needed to fairly assess Habitualism's explanatory merits. In Papineau's account: (A) what opposes intellectualists and habitualists is ultimately whether or not sporting skill involves "thought", as they contend whether reflection improves or rather harms the performance of expert athletes; $(\mathrm{B})$ while the control of Basic Actions functions better when it is deliberate, because it requires thought, the control of Motor Components is more efficacious when it is habitual and hence thoughtless.

If $A$ and $B$ were right, then Habitualism and Intellectualism would identify complementary territories of skilful expertise, defined by the presence/absence of thought, respectively. Like Fridland (2016), we find this conclusion debatable, but for different reasons: we worry that this framing might inadvertently and unjustly favour Intellectualism over Habitualism.

Against A, we observe that the Intellectualist notion of "thought" (typically understood by Intellectualists as a measure of cognitive effort) is inadequate to identify the cognitive requirements of sporting skills. In fact, the right question to ask is not whether action control is damaged by more or less thought, but whether the thoughts damaging performance are reflective in nature (thoughts about the task at hand) or rather distractive (thoughts unrelated to the task) (Cappuccio et al 2019). Note that, while intellectualists typically claim that performance disruption is alleviated by reflective thoughts and aggravated by distractive thoughts (choking by cognitive overload, Wine 1971), habitualists typically commit to the reverse claim (choking by self-monitoring, Beilock \& Carr 2001). This means that another notion of thought, focused on the quality of cognitive effort rather than its quantity, is both possible and needed.

Also B is prejudiced in favour of Intellectualism: it presumes that habits are thoughtless because they do not display the representational features (reflective goal-representation and content) that Intellectualism attributes to intentionality. Intentionality is the distinctive "directedness" or "aboutness" of mental activities, including all forms of thinking. We agree with intellectualists like Stanley \& Krakauer (2013) that actions can be skilful only insofar as some kind of intentionality governs them, harmoniously coordinating different movements toward a unitary purpose. However, we disagree that intentionality necessarily needs to have representational features. $B$ does not consider that other, non-intellectual varieties of intentionality (i.e., contentless, pre-reflective thought processes) exist and play a role guiding skilful performance (Moe 2016).

Rejecting the assumption that thought emerges only through reflective deliberation, we dispute both that thought belongs only to Basic Actions and that habitual dispositions control only Motor Components. What truly deserves to be debated is not whether a supplement of thought or intentionality, added to one's habits, can improve skilful action (there is broad consensus that both automatic dispositions and deliberate control contribute to sport 
performance), but what kind of thought or intentionality distinctively characterizes skilful performance and what its origin is.

In short, we propose to redefine Habitualism and Intellectualism as two opposite answers to the following question: do purposive intentions necessarily originate from top-down deliberative thought processes, or can habitual practice be their legitimate source too? Intellectualism answers that, in order to be intelligent and flexible, a motor behaviour must be informed by an intention that has an explicit goal representation as its specific content, which in turn can arise only from deliberative thought, not habitual behaviour; conversely, Habitualism answers that the expertise embedded in sensorimotor habits can produce a distinctively contentless intention that, without explicitly representing the action goal, can purposively drive skilful action in absence of deliberative thought.

\section{Four views on habit}

Redefining the Intellectualism/Habitualism demarcation this way helps us realize that their scopes are not complementary as they entail two incompatible views about the kind of intentionality involved in skilful action and, subsequently, the normative conditions that define skilful expertise. For Intellectualism, athletes are skilled if they are able to produce, through their action, a state of affairs that matches their explicit goals and plans, thus, skilful action aims to solve a practical problem bringing about a previously represented end-state. For Habitualism, athletes are skilled if they have the ability to detect and efficaciously respond with their bodies to certain familiar opportunities of action, thus, skilful action aims to confidently negotiate contingencies, adapting to environmental solicitations.

Note that not all intellectualists deny that skilful action requires the automatization of lowlevel Motor Components (e.g., Fridland 2019, Mylopoulos \& Pacherie 2019) and not all habitualists deny that deliberate control and explicit goal-representation can, in certain circumstances, improve the strategic control of Basic Actions (e.g., Hutto \& Sanchez-Garcia 2015). In order to accurately portray how both Habitualism and Intellectualism have diversified through decades of philosophical debate, we need to distinguish between an extreme (traditional) and a moderate (revised or liberal) version for each of these two views, thus identifying four competing positions contending the space of theoretical possibilities about skill. The following chart summarizes their main tenets about skilful performance: 


\begin{tabular}{|c|c|c|}
\hline Skilful action & \multicolumn{2}{|c|}{ Intellectualism vs Habitualism } \\
\hline \multirow{3}{*}{$\begin{array}{l}\text { Extreme (traditional) } \\
\text { versions } \\
\text { vs } \\
\text { Moderate } \\
\text { (Liberal/Revised) } \\
\text { versions }\end{array}$} & $\begin{array}{l}\text { Extreme Intellectualism } \\
\text { (EXINT) } \\
\text { Skilful action requires goal } \\
\text { representation and exclusively } \\
\text { relies on deliberate control, which } \\
\text { excludes automatic dispositions. }\end{array}$ & $\begin{array}{l}\text { Extreme Habitualism } \\
\text { (EXHAB) } \\
\text { Skilful action is incompatible with } \\
\text { goal representation and } \\
\text { exclusively relies on automatic } \\
\text { dispositions, which exclude } \\
\text { deliberate control. }\end{array}$ \\
\hline & $\begin{array}{l}\text { Liberal Intellectualism } \\
\text { (LIBINT) }\end{array}$ & $\begin{array}{l}\text { Revised Habitualism } \\
\text { (REHAB) }\end{array}$ \\
\hline & $\begin{array}{l}\text { Skilful action primarily relies on } \\
\text { deliberate control (which requires } \\
\text { goal representation at the level of } \\
\text { Basic Action), but is compatible } \\
\text { with automatic dispositions (at the } \\
\text { Motor Components level). }\end{array}$ & $\begin{array}{l}\text { Skilful action primarily relies on } \\
\text { automatic dispositions (which } \\
\text { require no goal representation at } \\
\text { the level of habitual behaviour), } \\
\text { but is compatible with deliberate } \\
\text { control (at the strategic, planning } \\
\text { level). }\end{array}$ \\
\hline
\end{tabular}

(Tab. 3) Varieties of Intellectualism and Habitualism about Skill

Note: Deliberate control is characterized by attentive decisions based on conscious reflection, while automatic dispositions are characterized by appropriate responsiveness to circumstances based on habit. When the normative conditions are explicit (goal representation) they depend on contentful models or sets of instructions (typically in a verbal, declarative, conceptual, or equivalent format), but when normative conditions are implicit (purposeful experience) they depend on dynamic adaptation (embodied responsiveness to affordances in the environment).

Assuming that only intentional action can have the kind of flexibility and purpose needed for skilful performance, adjudicating among these four positions means assessing whether habits can make skilful action flexible and purposive and whether an intentional action necessarily involves explicit goal representation. Traditionally, two philosophical approaches epitomize the most intransigent versions of Habitualism and Intellectualism, which contend the upper half of our schema.

Extreme Intellectualism (EXINT) assumes that action ensues when the body executes instructions previously represented in the mind: conceptual representations of action precede movement, motivating it with contentful intentions; intentions are centrally represented in the mind, and the body plays only a subordinate and instrumental role, as an 
executor; the body's ability to link together certain movements to speed-up their execution results from a more parsimonious use of the representational resources needed by deliberate control (Stanley 2011; Stanley \& Williamson 2017). Therefore, habit is a passive mechanism without inherent intelligence or purpose, an instrument serving the intellect's reasons and intentions.

Extreme Habitualism (EXHAB) is illustrated by the Absorbed Coping theory (Dreyfus 2002), which emphasizes that the development of skilful expertise entirely coincides with the progressive incorporation of habitual dispositions: skill learning occurs when action control becomes implicit; automatization of Basic Actions is not just an indicator of skilful expertise, but its very essence; Absorbed Coping and attentive, reflective control exclude one another. Explicit goal representation (deliberation, self-awareness, planning) is neither required by nor compatible with habitual dispositions, which are nonetheless intelligent, flexible, and richly adaptive. Experts absorbed in a pre-reflective flow of habitual activity skilfully adjust to environmental changes without needing or being able to access conscious knowledge of the Basic Action's goals or explicit representation of its Motor Components.

Ironically enough, both EXINT and EXHAB agree that reflective, conscious control is incompatible with habitual dispositions (Fridland 2014): an action is either deliberate or automatic, without mixes, because - they assume - goal representation informs the whole action execution or does not inform it all, without distinguishing between the global (Basic Action) and the local (Motor Components) level of the organization hierarchy.

\section{Liberal Intellectualism}

Distancing themselves from the extreme versions of Intellectualism and Habitualism, the latest iterations of this debate emphasise the unitary integration of thought and automatic behaviours, rather than their complementarity, stressing continuities more than specificities. We call Liberal Intellectualism (LIBINT) and Revised Habitualism (REHAB) the two theories contending this space. They distinguish strategic and sensorimotor control as two separate, parallel levels in the functional organization of skilful performance (corresponding to Basic Actions and Motor Components), allowing that the former is deliberate while the latter is automated.

LIBINT comprises the new wave of intellectualist approaches that follow this ecumenic trend. Despite their heterogeneity, all LIBINT views (e.g., Sutton 2007; Fridland 2014; Christensen, Sutton, \& Mcllwain 2016; Montero 2016; Brozzo 2017; Shepherd 2019; Elzinga 2019; 2019; Mylopoulos \& Pacherie 2019; Pavese 2019) agree with Habitualism that intelligence and flexibility are present in all skilful activities, including sport activities with a strong automatized component. LIBINT acknowledges that skilful activity is made possible by the deep integration of automated responses and deliberate control, criticizing the 
incompatibilism maintained by both EXINT and EXHAB (Sutton et al. 2011; Fridland 2013). In virtue of this integration, skilful activity can be "intelligent all the way down", with intentionality flowing from the Basic Action level (goal-oriented) into its Motor Components (Fridland 2016).

However, according to LIBINT, this continuity is possible when the skilful action as a whole, not its Motor Components, displays the kinds of intellectual attributes that EXINT has always associated with deliberate thinking: internally focused (self-aware, reflective), strategic (manipulating complex goal representations), working memory-consuming (i.e., using the content-involving variety of memory, as opposed to procedural memory, see Sutton 2007; Christensen, Sutton, Mcllwain 2016), and semantically integrated (i.e., informed by content-involving knowledge, McDowell 2007; Fridland 2016; Brozzo 2017).

Presuming that habits cannot be the source of such attributes, LIBINT infers that habitual behaviours are flexible and intelligent only insofar as a specific kind of intentionality with intellectual attributes informs action control in a top-down fashion. More specifically, the intellectual feature of intentionality that makes sport activity intelligent and flexible is representational content. Content reaches out to the habitual, contentless component to "mesh" with it (Christensen, Sutton, Mcllwain 2016) and give it a goal. Hence, the distinctive goal-orientation and flexibility of skilful action derives not from habitual dispositions, but from $\mathrm{Cl}$ (representational), which controls such dispositions without being part of them.

Some LIBINT views characterize these representations as propositional or conceptual in format, others as practical, motoric, or goal-oriented (Butterfill \& Sinigaglia 2012; Shepherd 2019; Pavese 2019). Either way, LIBINT consistently anchors the intentionality of skilled action to representational processes that, whether conceptual in nature or else, involve a content/vehicle distinction. LIBINT excludes that such processes could be sustained by contentless habitual dispositions, due to the alleged poverty of the sensorial stimuli that govern merely responsive behaviours (Brozzo 2017; Mylopoulos \& Pacherie 2019) ${ }^{1}$.

LIBINT considers intentionality and habits as conceptually distinct, as one of them is inevitably subordinated to the other: while the intentionality generated from high-level (representational) cognitive functions can inform habitual dispositions, LIBINT does not contemplate the reverse process: e.g., in the complex hierarchical diagram of motor control proposed by Mylopoulos \& Pacherie (2019), the arrows corresponding to intentional relations are exclusively top-down. LIBINT does not explicitly claim that habitual behaviour is merely instrumental in producing skilful performance, but neither does it state that habit

\footnotetext{
${ }^{1}$ The argument by poverty of the stimulus is one of the oldest used by cognitivism and is often invoked to demonstrate that internal, offline models (representations) are necessary to compensate for the alleged inability of on-line processes to generate sufficient criteria for perceptual decision.
} 
could be constitutive of or strictly necessary for skill (Toner, Montero, Moran 2014; Montero 2016).

Despite its integrative outlook, LIBINT is still fundamentally anti-habitualist because it preserves the intellectualist hierarchical model: goal-directed performances (Basic Actions) and habitual dispositions (Motor Components) differ because only the former, being representational, can be intentional. Habitual dispositions can play a role in controlling the Motor Components of skilful actions but, ultimately, automated responses cannot generate reasons or motivations of their own, hence they can be meaningfully coordinated only when they receive a goal from a representation. LIBINT presupposes that habitual dispositions can be intelligent and flexible when they are informed by appropriate goal-oriented representations but also that, by themselves, habits are just brute, inflexible and unintelligent mechanisms. While critically opposing the behaviourist accounts of sensorimotor skills (Sutton et al. 2011; Fridland 2019), LIBINT - no less than EXINT - still uses a set of behaviourist connotations to negatively characterize motor habits per se (i.e., automatic execution unaccompanied by representation).

Insofar as they are not legitimate sources of content, LIBINT accuses habitual behaviour of lacking two key features that only "thought" can give to action: intentionality (habitual behaviours do not bear a normative directedness or aboutness) and purpose (habitual behaviours are not motivated by reasons and preferences, hence they cannot have purpose, flexibility, or mindful awareness). Unless they are integrated in a series of deliberate actions, isolated motor habits lack these intellectual attributes, subsequently they ultimately are reducible to being: 1) unintelligent: "automatic behaviours", as opposed to "intelligent, fluid actions" (Fridland 2016; 2019, p.762); 2) inflexible: "invariant", "fixed", "ballistic" stimulusresponse associations (Fridland 2016, p.1541); and 3) mechanisms: as such, they have only a "brute-causal and bottom-up", "bodily" dimension, as opposed to intentional-anticipatory (Fridland 2016, p.1558).

This mechanistic view on habit can be historically traced back to Descartes (Sutton et al. 2011). Also William James conceived habitual actions as reflex-like, "rigid, automatic, unconscious, and opposed to goal-directed actions", i.e., "insensitive to feedback evaluation and blind to value changes in the anticipated effects" (Bernacer \& Murillo 2014). While LIBINT vigorously struggles to distance itself from this legacy, it does not offer a real alternative to it.

\section{Revised Habitualism}

Such an alternative is offered by recent developments in cognitive neuroscience that challenge the mechanistic view of the motor system and its functions (Cappuccio \& llundáinAgurruza 2020). The organization of the brain areas responsible for action coordination 
suggests that even simple motor programs display goal-directedness and flexible adaptivity to broad contexts of action (Graziano 2006). In sport, habitual dispositions select and shape attentional patterns, sustain the recognition of action opportunities, and fuel preferences and biases in intuitive decisions (Beilock 2008).

This suggests that motor habits, far from being reflexive mechanisms devoid of decisional abilities, are infused with a tacit form of practical know-how and situational awareness that originates from sensorimotor expertise and direct embodied engagement (Merleau-Ponty 2012). Significantly, the neuroscientists studying these intelligent features of the motor system refer to the Merleau-Pontian notion of $\mathrm{MI}$ to articulate the intuition that motor programs are intrinsically intentional and purposive (Rizzolatti \& Sinigaglia 2007).

MI also inspires the embodied approach that we call "Revised Habitualism" (REHAB). Like LIBINT, REHAB emphasizes that deliberative and automated processes can be deeply integrated and, unlike EXHAB, recognizes that strategic and reflective thought can play a role in skilful performance no less than automatic, pre-reflective processes (Cappuccio \& llundáin-Agurruza 2020). REHAB rejects the constraints put by EXHAB on expert performance: execution focus (without attention to component movements) interferes with automatized component movements, but that does not imply that the high-level control of habitual Basic Actions must be entirely unconscious and "mindless" (Cappuccio 2017). REHAB also rejects the negative characterizations given to habit by Intellectualism, contending that skilful action can be purposive, intelligent, and flexible even when it is solely determined by habitual dispositions. Two theoretical pillars sustain REHAB.

(I) Habitual behaviours (i.e., actions produced automatically), especially when skilful, are intentional just as much as deliberate actions (those produced reflectively), although the former and the latter are informed by two different varieties of intentionality, and, so to speak, two different kinds of "thought" or cognitive activity (Moe 2016). Both varieties are purposeful and inform the intelligent, flexible control of complex skilful actions. Each is characterized by normative conditions that define whether or not an action is successful. However, the former, $\mathrm{Cl}$, requires explicit representation of the action goal -whose success is measured by its correspondence to prior models or instructions. As for the latter, MI, involves no such representation: an action is successful when it appropriately responds to perceptual solicitations to act, i.e. environmental affordances.

(II) Habitual behaviours are not just informed by MI, rather they actively contribute to bringing about and contingently constitute motor intentions. Through the formation of sensorimotor habits, an agent acquires the kind of embodied practical knowledge necessary to: 1) read the environment in terms of opportunities for action; 2) motivate appropriate behavioural responses to such opportunities; and 
3) fluently control skilful actions to dynamically adapt to complex environments. Embodied interactive engagement with the environment is not only an effect, but also a source of MI. Habitual behaviours contribute to realize (motor) intentional processes exactly in the sense that, according to embodied cognition theory (Gallagher 2017; Cappuccio 2019), mental functions emerge from and are dynamically shaped and literally constituted by the bodily processes and activities that realise them. This is possible because the material vehicles that realize cognitive processes can be spread across brain, extra-neural body, and environment.

Skilful performance leverages automatized routines at various levels, which may involve not only single movements but also complex activities (e.g., daily exercise), thinking patterns (self-regulation), and even tactical attitudes (Cappuccio \& Wheeler 2012; Robbins \& Costa 2017). Habitual dispositions are not blind, rigid, reflexive reactions because they are constituted by person-level embodied activities. Indeed, habitual behaviour is not the outcome of sub-personal mechanisms, but a multi-layered phenomenon that -like other intentional activities- involves the human person as a whole, motivating her attitudes and preferences as an embodied situated agent embedded in a rich experiential environment.

To better grasp REHAB's commitments and implications, let us examine the seminal ideas of Maurice Merleau-Ponty in contrast to the mechanist account of habit.

\section{Merleau-Ponty on habit and Motor Intentionality}

In Phenomenology of Perception (Merleau-Ponty 2012), Merleau-Ponty introduces the notion of $\mathrm{Ml}$ to develop the idea that our basic relationship to the world is distinctively embodied and non-intellectual in nature. His account was inspired in part by the neuropsychological dissociation (famously exhibited by the patient Schneider) between two forms of motor control: the ability to perform habitual behaviours without exerting deliberative or reflective control, in response to the practical demands of the immediate situation; and the ability to perform abstract behaviours, which are by no means demanded by the immediate situation, in response to non-practical, verbal instructions. Schneider's condition spared the former but compromised the latter, despite him having retained the capability to understand the experimenter's verbal instructions. Merleau-Ponty accounts for this case by making MI play a double role to explain both how non-deliberate habitual behaviours can be skilful and how conceptual representations can guide the execution of the relevant motor sequences (Jensen 2009; Jackson 2018). The first aspect of this double role proves more important to elaborate what it means to say, along with REHAB, that habitual behaviours are not reducible to rigid mechanical routines and involve a form of intentionality different from $\mathrm{Cl}$. 
Three features of Merleau-Ponty's account are particularly relevant to sporting practice: (1) habits motivate purposeful behaviours without calling on goal-representation; (2) habits solicit similar types of purposeful behaviours in response to similar types of situations; (3) habits guide behaviours by shaping a practical form of situational awareness. To elaborate on these:

(1) Habits promote purposeful behaviours without calling on explicit goal-representation. For example, Schneider lost the capacity to produce actions based on conceptual representations of goals and action plans yet was allegedly capable of making wallets when thrown into the relevant situation. His action proceeded as if he were purposely aiming to make wallets and acting on his knowledge about the procedures to bring about this outcome. Given his condition, however, such goal representations or conceptual knowledge about the activity could not be playing a role in the production of his actions. The case demonstrates, accordingly, that well-trained habits are able to produce series of skilful movements organized in relation to an end state, even when the acting agent herself does not have this end in view. Merleau-Ponty first introduces the notion of $\mathrm{MI}$ in connection with this purposeful and anticipatory directedness to an end state exhibited both in habitual and non-habitual forms of embodied behaviour, which he describes as "an anticipation or grasp of the result assured by the body itself as a motor power" (2012, p. 113).

(2) Habits produce habitually consolidated types of responses to habitually consolidated types of situations. On the widely prevailing conception, habits consist of internal processes that rigidly reproduce the same specific sequence of responses when triggered by specific environmental cues associated with them (Wood and Rünger 2016). Habitual behaviours, however, rarely consist of exactly identical motor sequences. Even Schneider's habitual wallet-making action should manifest some degree of flexibility or variability depending on the specific variations of the situation: for example, the specific location of the materials and the qualities the latter exhibit (e.g. tougher or softer leather), or his specific sitting posture could not always be the same. In contrast to the prevailing conception, thus, Merleau-Ponty describes habit as "the power of responding with a certain type of solution to a certain form of situation" (2012, p. 143). Habitual behaviors are similar to one another not so much at the level of Motor Components as at the level of the types of practical goals towards which they are directed. 
Given Schneider's condition, however, this "power" cannot be based on the intellectual capacity to conceptually categorize situations and infer the appropriate type of response. Nor can it derive from one's factual knowledge about ways to execute certain types of performances. Accordingly, Merleau-Ponty holds that what lies at its basis is a system of sensorimotor processes that transforms sensory patterns into motoric patterns in a non-representational, yet lawful manner. This is what he calls the body-schema, "an open system of an infinity of equivalent positions in different orientations" in virtue of which "different motor tasks are instantly transposable" from one situation to another (Merleau-Ponty 2012, p. 142). These sensorimotor systems carry the agent's practical knowledge about how one can generate certain response patterns. Merleau-Ponty emphasizes, however, that this belongs to a different category from intellectual knowledge of facts: a habit, he writes, "is a question of knowledge in our hands, which is only given through a bodily effort and cannot be translated by an objective designation" (ibid, p. 145).

(3) Habits guide behaviours by shaping a practical form of awareness of the immediate situation. This contrasts with the prevailing conception of habitual behaviour as executed automatically and mindlessly, independently of conscious awareness (Wood and Rünger 2016; see also Ryle 2009; Dreyfus 2007). Merleau-Ponty suggests instead that motor habits guide action by enabling us to sense the practical significance of the situation. This is a basic form of situational awareness he calls "praktognosia" (2012, p. 141). It is very likely, for example, that people like Schneider perceive the workshop environment very differently from most of us who do not have the habit of making wallets from scratch. To put it in slightly different terms, sensorimotor habits allow us to perceive relevant action possibilities or affordances, which then solicit us to pursue a habitually consolidated course of action (Miyahara, Ransom, and Gallagher 2020).

Thus, according to Merleau-Ponty, habitual behaviours cannot be identified with stimulusdriven, rigid, mechanical routines. Rather, many instances of habits are penetrated by $\mathrm{Ml}$ in the sense that they are directed towards some purpose, flexibly adapted to the immediate situation, and sustained by a practical form of situational awareness that involves no mental representation. What makes REHAB significantly different from all other existing approaches to skill and practice is that it is premised upon this non-representational and anti-mechanist conception of habit. $^{2}$

\footnotetext{
${ }^{2}$ Due to spatial limitations, we will not discuss existing proposals to appropriate Merleau-Ponty's concept of MI into representational models of the mind (e.g. Butterfil and Sinigaglia 2012; Pacherie 2018; Mylopoulos and Pacherie 2019),
} 


\section{Sport psychology and Deliberate Practice}

Psychological research on skill acquisition suggests that sport training aiming at optimal habit formation is a cognitively demanding intelligent activity. Intellectualism might erroneously presume that this empirical datum undermines Merleau-Ponty's anti-mechanist view of habit. On the contrary, it actually corroborates it.

According to Ericsson (2016, p. 98), effective improvement of sporting skills always involves some form of "Deliberate Practice", defined as "purposeful practice that knows where it is going and how to get there". Practice is deliberate if the agent actively applies a purposeful and systematic attitude to maximize the efficacy of the learning process. Deliberate Practice is advertised as an alternative to the training methods based on the brute, mechanical repetition of motoric patterns: Ericsson (p.109) contests the "10,000-hour rule," the idea that learning a skill amounts to automatizing complex movements through a huge number of repetitions to acquire reflex-like habitual dispositions. REHAB agrees with the Deliberate Practice approach that the mechanical repetition of movements is neither the only nor primary form of skilled sport practice because habit formation hardly reduces to a blind, brute incorporation of unpurposive motor reflexes, although it may at times rely on it.

Montero (2016, p.129) writes that Deliberate Practice "prevents the attainment of automaticity" to support the thesis that skilful expertise cannot, in principle, be exclusively based on habit formation. Montero uses this interpretation of Deliberate Practice as an argument against Habitualism (the "just-do-it" principle, p.35), capitalising on the intellectualist assumption that a Basic Action must have a deliberate component because motor habits cannot be the source of its intentionality and purpose. As REHAB rejects this assumption, we propose to review the very notion of Deliberate Practice to assess whether it really contradicts Habitualism or not.

What Ericsson claims is that blind repetition of movement patterns may serve the acquisition of habits but not necessarily the development of real skill. Ericsson reminds us that habit and skill are distinct notions and should not be conflated because forming a habit does not necessarily amount to learning a skill. We agree that not all habits are conducive to skill development, and not all skills are primarily based on habit acquisition. But the nonidentity of habit and skill does not undermine our claim that habitual dispositions carry their specific form of intelligence and intentionality. The very notion of Deliberate Practice, as defined by Ericsson (2016), justifies different considerations about the nature of habit.

On the one hand, Ericsson recommends athletes to constantly question and revise their own habits without taking their efficacy for granted or blindly relying on them. Deliberate

limiting ourselves to mention that the attempts to explain skillful action in terms of representations or contentful states have raised conceptual objections by the theorists of embodiment and enaction (Gallagher 2017; Hutto \& Sanchez-Garcia 2015). 
Practice highlights the crucial importance of certain principles for skill training: (1) focus and concentration during exercise, valuing the quality of practice over quantity; (2) feedback systems to measure performance and implement evidence-based corrective strategies; (3) routine variation to leave the comfort zone and revise suboptimal habits; (4) learning objectives precisely set to measure the gap between current and desired state; (5) frequent analysis of activity during and after peak performance; and (6) measurement and management of stress so as to calibrate to a challenging but governable difficulty level.

Prima facie these characterizations seem to support the intellectualist view on skill learning: reflective attention is imposed top-down to discipline and constrain the trainee's bodily dispositions; routines are developed to be overcome; habits are acquired to be transcended. First person perspective know-how must be valued but can never be trusted: it must always be guided by evaluative and deliberative processes involving detached selfobservation.

Despite Ericsson's polemic against the "10,000-hour rule", however, Deliberate Practice theory never denies the importance of skill development through automatization: while critically questioning the exaggerated importance traditionally attributed to brute, repetitive exercise, it never denies that habit formation is a crucial component of skill acquisition and an active source of intelligent know-how. Therefore, if Intellectualism believes that Deliberate Practice is incompatible with Habitualism, it is once again because Intellectualism implies, at bottom, an essentially mechanist conception of habit.

Our thesis is that skill acquisition involves the development of very specific and intelligent habitual dispositions and that such dispositions have an inherent potential to support skilful performance, scaffolding both deliberate and automatic action through their specific motor intentional comprehension of the context. Ericsson's characterization of Deliberate Practice supports such thesis, confirming the positive role played by habit formation in skill acquisition. Ericsson's method appropriately emphasizes the importance of: (1) frequent repetition and continuity in exercise. Practice can take a considerable amount of time and repetitions; (2) setting local objectives. Tasks based on habitual behaviour must be divided into multiple subcomponents to be practiced independently, each with its own objectives and methods; and (3) accepting that practice is never definitively done. Habits are rarely acquired in a perfect and definitive form. As dynamic units of embodied know-how, habits are inevitably transient and old habits offer the conditions for the development of new ones.

Deliberate Practice highlights that not all habits are equally important for the development of a certain sport skill, which is why it suggests rational strategies to diversify habitual dispositions, select the most efficient ones, and optimize their effective integration in goaloriented activities. This is not incompatible with REHAB's notion of purposeful habit based on MI. 
What is incompatible with REHAB is Ericsson's appeal to mental representations as guides for action during both practice and peak performance (2016, p.50). Such an appeal identifies his view as LIBINT, because it implies that representational content is needed for skilful control. We believe that a non-representational interpretation of Deliberate Practice is possible and preferable. To sketch a different, non-representational version of Deliberate Practice theory, inspired by $\mathrm{MI}$ and compatible with REHAB, we will examine the cases of martial arts learning described in the Introduction, which illustrate the constitutive link between simple Motor Components and the goals of Basic Actions.

\section{Deliberate Practice in martial arts: Miyagi-sensei's routine}

As stated, we finally return to Karate Kid's training routine. Miyagi sensei's method suggests that repeating a sequence of movements (waxing on and off) can be useful to learn a new skill (karate blocking) even when the exerciser is unaware of the movements' real goal. Is Miyagi-sensei's method plausible, given these premises?

We are now in a position to see that the four answers indicated in the initial table correspond to our four views on skill acquisition.

\begin{tabular}{|c|c|c|}
\hline & \multicolumn{2}{|c|}{ Effective vs Ineffective exercise } \\
\hline & $\begin{array}{l}\text { EXINT } \\
\text { The routine's true goal is not } \\
\text { known but needs to be known. } \\
\text { The routine is USELESS } \\
\text { because it is just an AUTOMATIC } \\
\text { repetition of movements. }\end{array}$ & $\begin{array}{l}\text { EXHAB } \\
\text { The routine's true goal is not } \\
\text { known and does not need to be } \\
\text { known. } \\
\text { The routine is USEFUL } \\
\text { because it is just an AUTOMATIC } \\
\text { repetition of movements. }\end{array}$ \\
\hline $\begin{array}{l}\text { Automatic only vs } \\
\text { possibly deliberate } \\
\text { movements }\end{array}$ & $\begin{array}{l}\text { LIBINT } \\
\text { The routine's true goal needs to } \\
\text { be explicitly represented and can } \\
\text { be learned (verbally) after the } \\
\text { exercise. } \\
\text { The routine is USELESS unless } \\
\text { DELIBERATE exercise manages } \\
\text { to impose a new goal to old } \\
\text { motoric know-how. }\end{array}$ & $\begin{array}{l}\text { REHAB } \\
\text { The routine's true goal is } \\
\text { learned (motorically) through } \\
\text { exercise, but it does not need to be } \\
\text { explicitly represented. } \\
\text { The routine is USEFUL insofar } \\
\text { as DELIBERATE exercise helps } \\
\text { draw a new goal from an old } \\
\text { motoric know-how. }\end{array}$ \\
\hline
\end{tabular}

(Tab. 4) Different interpretations of Miyagi's method offered by the four views on skilful action. 
Both EXINT and EXHAB interpret Miyagi's method as entirely based on a "mindless" repetition of movements aiming to develop a responsive automatism. These views deny that this practice could have a deliberate component because, rejecting any compatibility between habit and explicit goal representation, they must exclude that the exerciser had any usable knowledge of the routine's real goal. However, the former considers goal representation necessary to skilful control, the latter considers it unnecessary or even problematic, which is why they give opposite judgements about Miyagi's method.

EXINT understands Miyagi's method as a sort of brute muscular training. Its only utility, if there is one, is increasing "motor acuity", i.e. the ability to reproduce the same motor sequence more accurately, lessening the chance to fail. However helpful this is, an increased motor acuity cannot facilitate the development of an adaptive and predictive skilful ability like karate blocking because "motor skill depends on knowledge of facts" (Stanley \& Krakauer 2013): without explicit representation of the routine's true goal, the action learned is not guided by the right kind of intention and hence cannot acquire the necessary flexibility and intelligence.

EXHAB, on the other hand, finds Miyagi's method perfectly viable: automatizing a motor routine is sufficient to effectively deploy a skilful action, and knowing the routine's goal is not necessary for such automatization to occur. But how can the learner suddenly cope with the unfamiliar karate context and recognize its unique action opportunities if the motor habits he has acquired are tailored to the waxing context? To allow the possibility that the Motor Components of a waxing action were reused to perform a blocking Basic Action, EXHAB needs to explain how a familiar action's goal can be practically equivalent to the unfamiliar one's. EXHAB cannot explain the voluntary transition from one skill to another without recognizing that Deliberate Practice is exactly what allows an expert to consciously adapt the fine-grained details of their familiar actions to new, unfamiliar contexts. Therefore, either EXHAB remains unable to explain the transition between skills, or it accepts that deliberation can be part of skilful control, effectually turning into REHAB.

LIBINT and REHAB offer more sophisticated accounts of the training routine because they allow for the possibility that the automated component of the action (the motor habits) can be integrated by deliberate control. This may happen when the exerciser is made aware that the blind repetition of waxing movements was actually meant to learn a karate blocking skill. The difference between LIBINT and REHAB is nuanced, but significant.

For LIBINT the training routine is useful only if old habitual dispositions are appropriately mapped into new goal representations. The effectiveness of Miyagi's method strictly depends on the trainee's ability to transfer to the karate context the function of the Motor Components previously acquired in the waxing context, guided by a new goal representation. This presupposes that new goals can be imposed to familiar motor routines 
through a top-down process, deliberately modulating the action's motoric profile. However, the significant differences between the two contexts, instead of facilitating the trainee, would end-up doubling the required effort: first, Daniel-san has to learn waxing movements and subsequently how they can be suited to realize an entirely different kind of action. This is theoretically conceivable, but practically improbable and obviously inconvenient: learning that the action's real goal is blocking certainly is not enough to tell the body how blocking must be done.

Unlike LIBINT, REHAB does not view Motor Components as goal-neutral because each of them, so to speak, "knows" from the beginning which Basic Actions it can produce: the motoric know-how acquired during the formation of habitual responses already identifies a broad set of possibilities of competent and fast application. Certainly, re-practicing waxing movements within a karate context, effortfully trying to conceive them as components of a blocking routine, does not help developing a fluid and rapid enough goal-oriented action. In this sense, the sudden, almost miraculous, skill development portrayed by the movie may be misleading. We can truly understand the real usefulness of Miyagi-sensei's exercise only if we stop thinking that it was meant to impose on a set of familiar movements the goal of an action that is explicitly represented yet motorically unfamiliar. REHAB helps us see the reverse process: the aim of Miyagi-sensei's practice is not to produce new movements using explicit knowledge of the action goal, but to concretely leverage the trainee's familiarity with well-trained movements to let the implicit possibility of an unknown goal-oriented action arise as a new form of embodied awareness. If Miyagi-sensei does not explicitly instruct Danielsan to execute a blocking move it is because it would be pointless at such an early stage: the practical significance of the "blocking" goal cannot be explicitly known by the mind of the learner if the learner's body has not already incorporated it in its motoric repertoire.

Consider typical karate training. During practice, skilled performers deliberately repeat again and again the same punching movements. They do it slowly, purposefully, and attentively monitoring the gross motor profile of a Basic Action (the punch as a whole) and its Motor Components, scanning sequentially through its fine-grained kinematics as they unfold the punch as a unified sequence: the punch ultimately fits in the larger context of an effective offensive combat action because it discloses such context as a concrete possibility. Similarly, from a REHAB perspective, the "wax on wax off" exercise seen in Karate Kid may work as a controlled simulation to conduct such slow monitoring. Such a simulation cannot magically create a new skill from scratch through rote repetition only, but it can be an extremely effective method to guide the development of one's emergent habitual dispositions through Deliberate Practice, leveraging the embodied responses that the exerciser is in the process of developing through repetition. 
Karate Kid reminds us that martial arts learning mobilises at once top-down and bottomup processes, unifying sensorimotor and doctrinal elements through a circular movement that involves the whole hierarchical organization of skilful action, recurrently recruiting all its different levels of granularity (llundáin-Agurruza 2016):

1. Motor Components of Basic Actions, including fine-grained kinematic details like a wrist's minimal pronation or the gliding and "just-so-angled" foot when the leg advances.

2. Basic Actions such as a punch, block, or kick. A simple punch simultaneously engages fist rotation, punching arm extension and retraction of the other arm (while also counter-rotating fists), and hip torsion - the source of power - while stepping (these divide further into 1).

3. Action sequences of full-fledged martial practice. The previous two elements are foundational for the more complex aspects of: a) kata, movement patterns of concatenated punches, kicks, blocks, etc., b) improvised movement sequences against imaginary opponents, c) partner practice of either planned kata movements or randori free-style practice sparring against one or several opponents, and d) actual combat.

4. Doctrinal and cultural dimensions of the martial art: context-dependent normative differences, between traditional martial art and contemporary "sportified" variations, and differences between seemingly identical actions, e.g., zanshin - the "remaining spirit" or intense focus after a successful hit - which is vital in traditional Japanese kendo but largely incidental for the sport-like kumdo Korean counterpart.

Which of the four views on skill can best account for the organic interconnection between these four levels? Habitualism emphasizes the automatization of the swiping movement (levels 1 and 2); Intellectualism focuses on the pedagogical transmission of models and doctrines (levels 3 and 4). LIBINT recognizes their connection, but sees it only as a topdown process (from 4 to 1). Only REHAB, considering both top-down and bottom-up connections as necessary, can organically account for the four elements of Deliberate Practice at once and explain how the preparation of martial skills needs that the "simple" block action is fluidly connected with the complex sequences of a long kata or the tactical demands of actual combat. REHAB offers the most comprehensive and accurate account because it explains how both high-level cognitions and low-level motor habits each play a vital role bringing about two specific forms of intelligence. 


\section{Conclusion}

Having recognised the true significance of Miyagi-sensei's method, we can acknowledge that REHAB is not just compatible with Deliberate Practice: rather, it is the only philosophical account of habit genuinely able to make sense of it. EXHAB presupposes that mastery of Motor Components is sufficient for intelligent adaptation; EXINT that mastery of intelligent adaptation is sufficient to control Motor Components. Both assumptions are wrong. Without deep integration, practice cannot be deliberate, performance cannot be context-sensitive, action cannot be fluid and adaptive. LIBINT correctly sees the need for such deep integration but construes it in the wrong way, assuming that practice can be entirely guided through representational and reflective aspects alone, e.g., verbal instructions and explicit goal understanding. This construction overlooks that instructions and goals (know-that) make truly sense only after familiarity with actual practice of Motor Components (know-how) is acquired. REHAB is aware of this lesson, and proposes to understand the waxing routine not as a trick to get around the deliberate efforts necessary to develop a skill, but as an engaged way to build a background of concrete familiarity against which the goals of the new skills can practically make sense to the exerciser.

Obviously, not all habits are skilful or virtuous, which is why habit formation does not always lead to skill development. Deliberate Practice highlights that sport expertise involves more than just habits: it involves habits specifically acquired to achieve an adequate purpose, which in turn can be comprehended only if specific body schemata have prepared the agent to make sense of a new pragmatic context. What LIBINT overlooks is that, just because habits are motivational dispositions to act, habit formation is accompanied by its specific creation of purpose, which explains why the purpose embedded in well-practiced movements can transfer from an interactive context to another.

This is nicely illustrated by another practice portrayed in the Karate Kid movie: the balancing exercise based on standing in a rowboat at sea. Practicing balance is paramount to acquire the poised and polished posture needed during a match against an adversary. But the habit's purpose is somehow the same during the rowboat training and in combat because the motoric components themselves carry intentional connotations and can disclose meaningful implications for the person as an autonomous whole. Balance training is universally valuable because it is equally central to achievement in the ring, on a rowboat, and in life.

Both waxing and skilful balancing are instances of skilled performance involving purposeful habit formation without explicit goal representation. As examples of Deliberate Practice deeply rooted in habit formation, they make straightforward counter examples to Intellectualism: intellectualists can explain why habit formation does not always lead to skill acquisition (skilled performance may need deliberate decision-making, which is not 
reducible to dispositions), but they fail to explain why habit formation can in some cases constitute skill development in itself.

Low-level actions, like the movements instantly produced and modified on the go by martial artists in response to their opponents, are intelligently semi-autonomous precisely because they are automatized and contentless. The possibilities to consciously and deliberately modify one's expert actions are disclosed, not constrained, by this skilful automaticity: that is why the capability to match intended outcomes to well-trained movements is the prerogative of skilled performers, not novices. Pace Intellectualism, automatism is not a drawback for precise, flexible control and improvisation, but rather lays their pragmatic foundation.

We have argued that REHAB's non-representational approach provides the best explanation of how habitual dispositions contribute to skilled action. The potential autonomy from intellectual, content-involving features makes automated action flexible, precise, and anticipatory for situation-aware, rapid responsiveness to contextual circumstances. As such, it emerges bottom-up from embodied know-how via Ml and cannot be imposed by explicit models or instructions based on representation. Expert martial artists can dynamically and improvisationally adapt to varying adversaries, conditions (e.g., attention and stamina), and environmental factors just because their well-practiced moves, incarnating both motoric know-how and experiential awareness, dynamically maintain an optimal grip on these key variables. As REHAB is the only theory able to account for this "knowledge in the hands", it provides a richer account of habit than EXHAB or Intellectualism alone, and a compromising but ultimately unsatisfying LIBINT.

\section{Acknowledgments}

This work was supported by the Australian Research Council Discovery Project 'Minds in Skilled Performance' [DP170102987].

\section{References}

Beilock SL (2008) Beyond the playing field: sport psychology meets embodied cognition. International review of sport and exercise psychology, 1(1), pp.19-30.

Beilock SL, Carr TH (2001) On the fragility of skilled performance: what governs choking under pressure? Journal of experimental psychology. General, 130(4), 701-725. 
Bernacer J, Murillo $\mathrm{Jl}$ (2014) The Aristotelian conception of habit and its contribution to human neuroscience. Frontiers in human neuroscience, 8, 883.

Butterfill SA, Sinigaglia C (2012) Intention and Motor Representation in Purposive Action. Philosophy and phenomenological research, 88(1), 119-145.

Cappuccio M, Wheeler M (2012) 'Ground-level Intelligence: Action-Oriented Representation and Dynamics of the Background', in Radman Z (ed.), Palgrave Macmillan, The United Kingdom.

Cappuccio ML (2017) Flow, choke, skill: The role of the non-conscious in sport performance. In Z. Radman (Ed.), Before consciousness: In search of the of the Fundamentals of Mind, Imprint Academic.

Cappuccio ML (2019) Introduction. Handbook of Embodied Cognition and Sport Psychology, i-xxii.

Cappuccio ML, Gray R, Hill D, Mesagno C, Carr T (2019) The Many Threats of SelfConsciousness: Embodied Approaches to Choking under Pressure in Sensorimotor Skills. Handbook of Embodied Cognition and Sport Psychology, 101-156.

Cappuccio M \& Ilundáin-Agurruza J (2020) Swim or Sink. Habit and Skilful Control in Sport Performance. F Carauna \& I Testa (eds.) Habits. Pragmatist Approaches from Cognitive Neuroscience to Social Science, Cambridge University Press.

Christensen W, Sutton J, Mcllwain DJF (2016) Cognition in Skilled Action: Meshed Control and the Varieties of Skill Experience. Mind \& language, 31(1), 37-66.

Dreyfus H, Dreyfus S (1986) Mind Over Machine: The Power of Human Intuition and Expertise in the Era of the Computer (New York: The Free Press

Dreyfus H (2002) Intelligence without representation: Merleau-Ponty's critique of representation. Phenomenology and the Cognitive Sciences, 1, 367-383.

Dreyfus $\mathrm{H}$ (2007) The return of the myth of the mental. Inquiry 50: 352-365

Elzinga B (2019) Intellectualizing know how. Synthese. 
Ericsson A, Pool R (2016) Peak: Secrets from the New Science of Expertise. Boston: Houghton Mifflin Harcourt.

Fitt M \& Posner MI (1967) Learning and skilled performance in human performance. Belmont, CA: Brock-Cole.

Fridland E (2013) Problems with Intellectualism. Philosophical studies, 165(3), 879-891.

Fridland E (2014) They've lost control: reflections on skill. Synthese, 191(12), 2729-2750.

Fridland E (2016) Skill and motor control: intelligence all the way down. Philosophical studies, 174(6), 1539-1560.

Fridland E (2019) Longer, smaller, faster, stronger: On skills and intelligence. Philosophical psychology, 32(5), 759-783.

Gallagher S (2017) Enactivist interventions: Rethinking the mind. Oxford University Press.

Graziano M (2006) The organization of behavioral repertoire in motor cortex. Annual review of neuroscience, 29, pp.105-134.

Hutto D. D. \& Sanchez-Garcia, R. (2015) Choking RECtified: embodied expertise beyond Dreyfus. Phenomenology and the Cognitive Sciences, 14 (2), 309-331.

Ilundáin-Agurruza J (2016) Holism and the cultivation of excellence in sports and performance: Skillful striving. London: Routledge.

Jackson GB (2018) Maurice Merleau-Ponty's concept of motor intentionality: Unifying two kinds of bodily agency. European Journal of Philosophy, 26(2), 763-779.

Jensen RT (2009) Motor intentionality and the case of Schneider. Phenomenology and the Cognitive Sciences, 8(3), 371-388.

Kelly S (2000) Grasping at straws: motor intentionality and the cognitive science of skilful action. In: M. Wrathall and J. Malpas (eds), Heidegger, Coping, and Cognitive Science: Essays in Honor of Hubert L. Dreyfus-Vol. II, 161-177. Cambridge, MA: MIT Press. 
McDowell J (2007b) Response to Dreyfus. Inquiry 50 no. 4: 366-370

Miyahara K, Ransom T G, Gallagher S (2020) What the situation affords: Habit and heedful interrelations in skilled performance. Caruana Fausto and Italo Testa (eds.), Habit: Pragmatist Approaches from Cognitive Neurosciences to Social Sciences (Cambridge: Cambridge University Press).

Moe VF (2016) On phenomenological and logical characteristics of skilled behaviour in sport: cognitive and motor intentionality. Skills, Knowledge and Expertise in Sport, 35-52.

Montero BG (2010) Does bodily awareness interfere with highly skilled movement? Inquiry, 53(2), 105-122.

Montero BG (2016) Thought in Action: Expertise and the Conscious Mind, Oxford University Press.

Mylopoulos M \& Pacherie E (2019) Intentions: The dynamic hierarchical model revisited. Wiley Interdisciplinary Reviews: Cognitive Science 10 (2), e1481

Pacherie E (2018). Motor intentionality. In Newen A, De Bruin L, Gallagher S (eds) The Oxford Handbook of 4E Cognition. Oxford University Press, Oxford

Papineau D (2015) Choking and The Yips. Phenomenology and the Cognitive Sciences, 14(2), 295-308.

Pavese C (2019) The psychological reality of practical representation. Philosophical psychology, 32(5), 784-821.

Rizzolatti G \& Sinigaglia C (2007) Mirror neurons and motor intentionality. Functional neurology, 22(4), 205-210.

Robbins T W \& Costa R M (2017) Habits. Current Biology. Cell Press.

Ryle G (2009) The concept of mind. Oxon: Routledge. 
Shepherd J (2019) Skilled Action and the Double Life of Intention. Philosophy and phenomenological research, 98(2), 286-305.

Stanley J (2011) Know how. Oxford: Oxford University Press.

Stanley J, Williamson T (2017) Skill. Noûs, 51(4), 713-726.

Stanley J, Krakauer J (2013) Motor skill depends on knowledge of facts. Frontiers of Human Neuroscience.

Sutton J (2007) Batting, Habit and Memory: The Embodied Mind and the Nature of Skill. Sport in Society, 10(5), 763-786.

Sutton J, Mcllwain D, Christensen W, Geeves A (2011) Applying intelligence to the reflexes: embodied skills and habits between Dreyfus and Descartes. Journal of the British Society for Phenomenology, 42(1), 78-103.

Toner J, Montero BG, Moran A (2014) Considering the role of cognitive control in expert performance. Phenomenology and the Cognitive Sciences, 14(4), 1127-1144.

Wine J (1971) Test anxiety and direction of attention. Psychological Bulletin, 76(2), 92104.

Wood W, Rünger D (2016) Psychology of habit. Annual Review of Psychology 67: 289$314 s$ 